\title{
Bridging the Water Supply-Demand Gap in Australia: Coupling Water Demand Efficiency with Rain-independent Desalination Supply
}

\author{
Oz Sahin ${ }^{a} \&$ Rodney A. Stewart ${ }^{\mathrm{a}} \&$ Fernanda Helfer $^{\mathrm{a}}$ \\ ${ }^{a}$ Griffith school of Engineering, Griffith University, Queensland, Australia
}

\author{
Corresponding author: \\ Oz Sahin \\ Griffith School of Engineering, \\ Gold Coast Campus, \\ Griffith University, QLD 4222, Australia \\ Phone: +61 755528778 \\ Email: o.sahin@griffith.edu.au
}

\begin{abstract}
Water supply in Australia mainly relies on precipitation and, therefore, is highly dependent on climate variability and change. Coupled with reduced rainfall reliability, population and economic growth and increasing competition for water resources augment the concern over the existing water resources and put a strain on future water security. In fact, the upward trend of water demand has already been escalating the pressure on water resources. Clearly, the anticipation of decline in water supply requires the identification of more reliable, rainfall-independent supply alternatives. With this in mind, this paper discusses the role and value of desalination in water grids. For this purpose, we present a modelling framework using System Dynamics approach to incorporate a range of factors into a simulation of future water demand and supply in Queensland, Australia; and examine desalination schemes as long-term water security option in the portfolio of supply sources. In particular, the model is used to explore the sensitivity of long term planning of water resources with respect to two specific assumptions, the discount rate and the degree of water security. The proposed approach would help decision makers to develop sustainable water supply and efficient infrastructure strategies, and thus respond to water scarcity in a timely manner.
\end{abstract}

Keywords: Desalination; Water security; Water supply and demand; System Dynamics; Water resource management 


\section{INTRODUCTION}

Australia, the driest inhabited continent, has the highest per capita surface water storage capacity of any country in the world. The large number and size of water storages is a result of both Australia's aridity and the highly variable rainfall, and yet until recently Australia's water supply fully relied on precipitation (ABS 2010; ABS 2012). The problem of securing enough water for human requirements in Australia is not an issue of insufficient water resources, but rather an issue of water balance, or more accurately stated, water imbalance (NCEDA 2010).

Rainfall in Australia is highly variable, and most cities rely heavily on dams with a very large aggregate storage capacity. Particularly, South-East Queensland (SEQ) in 2006 had by far the largest ratio of storage to annual usage $\left(1,800: 300 \mathrm{hm}^{3}\right)$, reflecting the extreme variability in annual rainfall (Marsden and Pickering 2006). Following years, the SEQ storage capacity has been further increased and reached 2,200 $\mathrm{hm}^{3}$ in 2013 (BOM 2013) reflecting the water authorities' concerns in meeting the future water needs, and yet not decreasing reliance on rainfall-dependent water sources, which account for 96.4 percent of total storage capacity.

Evidently, having a large storage capacity mainly at the mercy of rainfall does not provide water security. For example, as a result of six consecutive years of drops of storage level, the accessible volume fell below $40 \%$ accessible capacity in 2007 , and subsequently more than two million people in SEQ were subject to the highest level of water restrictions, which limited residential per capita consumptions from about $450 \mathrm{~L} \mathrm{day}^{-1}$ to $140 \mathrm{~L} \mathrm{day}^{-1}$ in 2007 (QWC 2010).

Further, the climate change expected to cause a reduction in water supply and a significant drop in annual mean flow 16 to $48 \%$ by 2100 (Hennessy et al. 2007) and increased water demand due to the growing population and economy would intensify the pressure on supply availability over time.

Given the inherent uncertainty of climate variability and change, and changing temporal and spatial patterns of rainfall, a key question is: 
What should be done to reduce uncertainty and provide water security insurance to cope with the water scarcity problems caused by changing climate and population growth?

In an attempt to strengthen water security in their region, water authorities are implementing a range of drought-proofing measures. Water demand management strategies are considered to be the lowest cost water security measure and have the potential to significantly reduce consumption of a region in terms of system leakage (Girard and Stewart 2007), household leakage (Britton et al. 2013), water efficient appliance retrofits (Beal and Stewart 2011; Willis et al. 2013), and water consumption behavioural change communication and technologies (Fielding et al. 2013; Stewart et al. 2011; Willis et al. 2010; Willis et al. 2011a). Residential water consumption in the study region dropped by 50\% between 2005 and 2014 (Beal and Stewart 2011) and the rapid diffusion of the above-mentioned technologies will lead to a long-term reduction in water demand over time. However, demand management alone will not alleviate the supply deficiency created by a rapidly growing population in SEQ.

Once demand management strategies are exhausted and a city moves to an efficient per capita demand level, a range of rain-dependent and rain-independent solutions such as desalination (desal) are often explored. These water supply solutions are either large-scale centralised (e.g. dams, seawater/groundwater desal, stormwater/wastewater recycling plants, etc.) or small-scale distributed systems (rainwater harvesting systems, communal recycling systems, etc.). Centralised raindependent supply schemes such as dams can often be the lowest unit cost option but in recent times are often politically and environmentally challenging to implement in urbanised areas (Wasimi 2010) and decentralised schemes such as rainwater harvesting can have high unit costs (Stewart 2011) with no guarantee of yield during extended droughts (Vieira et al. 2014). Decentralised rainindependent schemes such as onsite recycling and reuse in multi-residential buildings are a sustainable way to reduce demand but often have a very high unit cost due to their capital cost and ongoing maintenance which is shared by a relatively small number of users (Gurung and Sharma 2014). Larger scale rain-independent dual pipe recycling schemes (i.e. one potable and one recycled 
pipe per customer) are also an effective way to reduce potable supply requirements in a city (Willis et al. 2011b), but have a very high unit cost when compared to other alternatives due to the requirement to provide twice the amount of distribution infrastructure (Stewart 2011). While largescale rain-independent schemes such as desal and indirect-potable reuse recycling have the disadvantage of being more energy intensive than rain-dependent schemes, they provide a reliable supply source for coastal cities at a comparably lower unit cost than decentralised rain-independent schemes (Stewart 2011). In the large and fast-growing coastal urban region of SEQ, desal is the most viable lowest unit cost bulk supply solution to complement the regions' ongoing best practice in demand management. It is acknowledged that a number of small distributed systems will also feature in the supply mix in this region in the future, but including them in this present bulk supply model is not feasible and considered outside of the scope for the herein strategic modelling process.

In this context, the primary objective of this research is to develop a system dynamics model for evaluating the SEQ bulk water supply system water balance for a number of bulk water supply source futures over a 100 year life cycle and addressing the following issues:

- The impacts of desalinated supply in providing urban water security and reliability in the short and long terms under the influence of changing climate and population growth scenarios,

- Quantification of the benefits of ongoing water efficiency strategies (i.e. appliance retrofits, smart metering, leak management, etc.) to reduce the number of desal plants the region requires to maintain its water security when compared to historical demand trends.

- The effects of desal as an insurance policy for bridging the gap between supply and demand, particularly, during times of drought and provide water security, and

- Comparison of costs of water supply augmentation alternatives.

Thus, the research focuses on demand, supply, climate change, extreme events and population growth, and critically on the impacts of having (or not having) desal plants on call. The research evaluates current and future conditions under a range of scenarios, including sustained per capita 
demand reduction, construction of new desalination plants and dams, changes in precipitation due to climate change, water restriction, and population growth. It must be noted that, in this article, water security refers to a sufficient water supply meeting the needs of urban, industrial and rural growth and the environment; and reliability refers to frequency and duration of unplanned supply interruption or shortages.

\section{METHODOLOGY}

\subsection{Study Region: South-East Queensland, Australia}

This research was conducted in the SEQ, Australia (Figure 1). In 2013, the SEQ region had an approximate population of 3.2 million people. According to the Queensland Government's Population Projection Report the annual population growth rate is currently $2.0 \%$, and is projected to slow over the 45 year projection period to 1.2 per cent per annum in 2056 (Queensland Treasury 2011). Total urban water demand accounts for approximately $65 \%$ of SEQ's total water usage (QWC 2010; QWC 2012). Further, water security has and will continue to become one of the key risks in this region, similarly to many other regions across Australia, as stream flows are expected to decline between $16 \%$ and $48 \%$ by 2100 due to a changing climate (Hennessy et al. 2007). As a result, the reliability of water supply would deteriorate due to reduced water supply from traditional sources (such as dams and aquifers) for urban users and supplies becoming more variable within season and over time. 


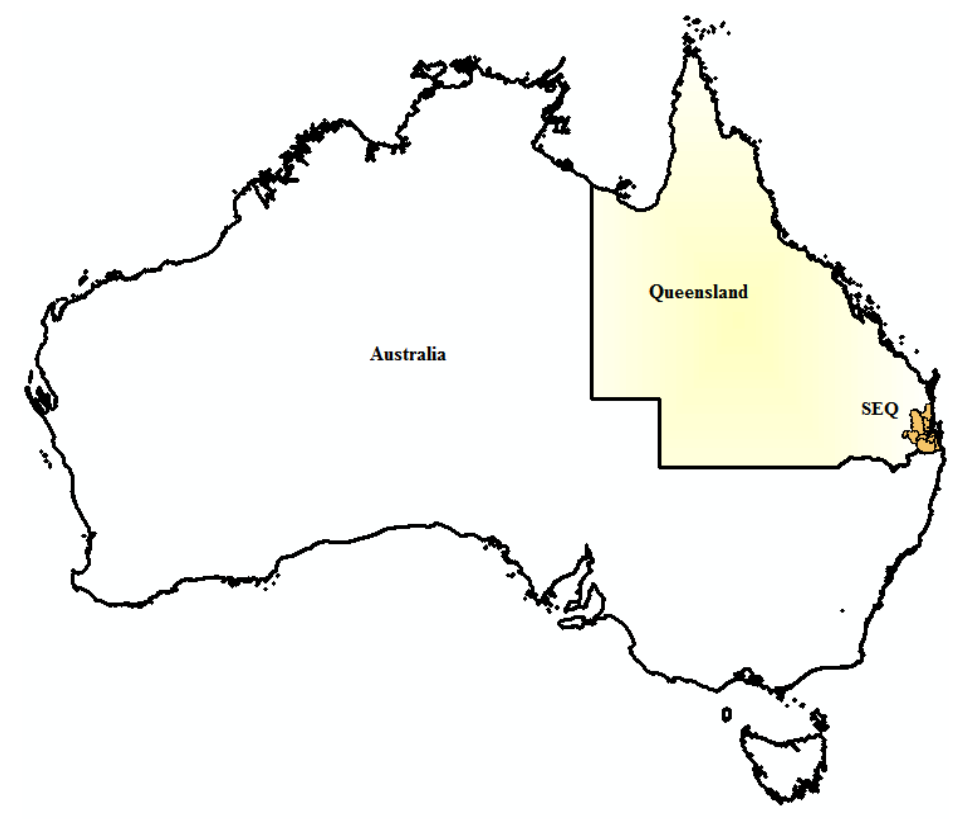

Figure 1 Study region: South East Queensland, Australia

The SEQ region, like many major cities in Australia, predominantly $(96 \%)$ rely on surface water reservoirs (NCEDA 2010). Such a high proportion of rain-dependent supply sources means that SEQ, like most Australian cities, requires a large storage buffer against low rainfall years (Marsden and Pickering 2006). Dam inflow yields are particularly susceptible to the effects of global climate change as well as to natural climate variability (NCEDA 2010; NWC 2006). The accessible water storage capacity and volumes of reservoirs supplying the SEQ region is 2,200 $\mathrm{hm}^{3}$ (BOM 2013). Despite having such a large storage capacity, which represents over six years of supply at current demand levels, the accessible volume dropped below 40\% accessible capacity in the 2002-2007 drought period, and in many instances, as reported by Willis et al. (2013), many reservoirs dropped below 20\%. Accordingly, a preparatory approach has been adopted in the region (QWC 2012), which introduced drought storage reserves and pre-defined trigger levels (40\% combined capacity) to drive a prepared response should water storage levels become critical. At this point, the drought response plan, which includes a combination of applying medium level restrictions, introducing the existing purified recycled water to the water grid and constructing new climate resilient supplies, would be triggered. 


\subsection{Systems Approach}

Water systems, like most complex environmental issues, are highly dynamic and characterized by feedbacks, interdependencies, and discontinuous non-linear relations of their elements. In this context, System Dynamics (SD) modelling offers a suitable platform for exploring complex water systems. Therefore, in this research, the SD modelling approach was employed to investigate the water system in SEQ as well as conduct scenario analysis. Simulation models play an important role in the water management process. In addition to predicting the future state of the system, models are used for exploration, communication, and analysis. Simulation in this context is intended to present a powerful tool for analysing different options and understanding the long-term implications of management decisions. Simulation, as defined by Borshchev and Filippov (2004), is the process of model execution that takes the model through (discrete or continuous) state changes, over time. Therefore, simulation modelling is a better answer for complex problems where time dynamics are important.

$\mathrm{SD}$ is a powerful methodology and computer simulation modelling approach, which was originally rooted in the management and engineering sciences (Forrester 1961). Gradually, it spread into other fields, including social, economic, physical, chemical, biological, and ecological systems. System dynamics models have evolved and are used today to simulate complex systems behaviour in public health (Cavana and Clifford 2006; Homer et al. 2007; Homer et al. 2004); energy and the environment (Fiddaman 1997; Fiddaman 2002; Ford 2005; Sterman 2008) irrigation systems and water quality (Gharib 2008; Zhang 2008); climate change impact assessment and adaptation modelling (Burton et al. 2002; Franck 2009; Marchand 2009; Sahin 2011; Sahin and Mohamed 2009; Sahin 2013) and many other fields.

System diagrams (or conceptual models) are important tools in systems analysis. A system diagram represents cause-effect relations between elements or sub-systems of the overall system (Loucks and van Beek 2005). These components form feedback loops that are linked with other feedback loops. Feedback is a process whereby an initial cause ripples through a chain of causation, 
ultimately to re-affect itself (Roberts 1983). The interaction between these feedback loops is not linear. That is, an identical change in one component may not always cause the same system behaviour as there may be a change in the state of the system, over time. The system diagram used in this project for analysing water resources problems is presented in Figure 2.

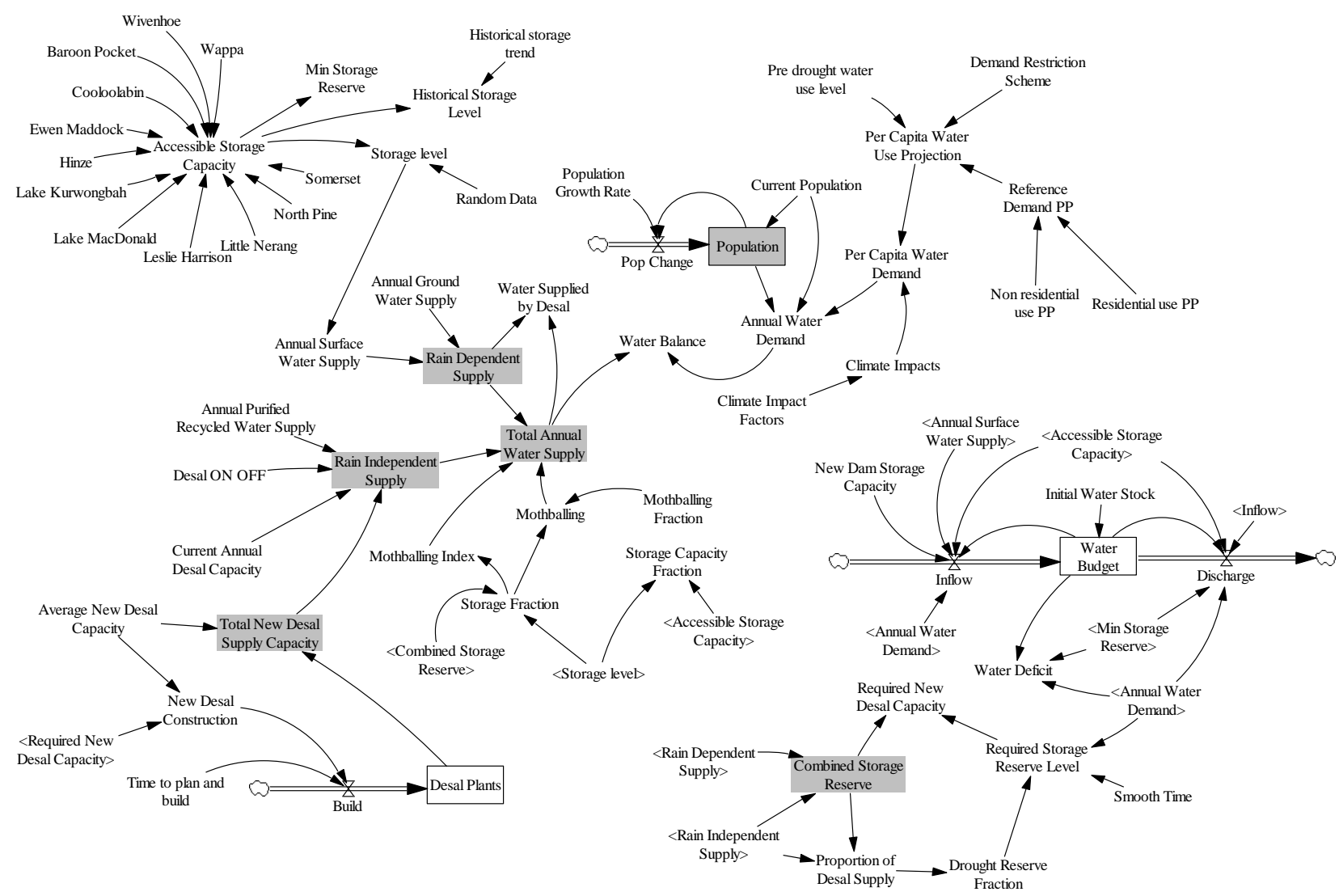

Figure 2 The System Dynamics model showing key variables and their causal relations

\subsection{Modelling Architecture}

As illustrated in Figure 2, the proposed model describes the system being analysed and conditions that the system has to satisfy. These conditions are often called constraints. The model is composed of five main categories capturing the demand, supply, climate change, population growth, and impacts of desal plants on water supply as there is a strong interdependency between these categories, and it is, therefore, important to coordinate these interdependencies effectively within a modelling framework. The SD model simulates current and future conditions by 
considering the effects of population growth, climate change and desal plants on water supply and demand.

Simulation involves determining the effect of decreasing one or more key factors and simultaneously increasing one or more other key factors in a decision model. That is, the model deliberates various scenarios and alternatives (i.e. groundwater, a new desal plants, a new reservoir, climate change, and population growth), and provides better visualization of how water supplies and demands vary in the system over time, including any feedbacks that might cause unexpected changes in other parts of the system. These feedbacks are often difficult to understand and explain without a model.

The model built by using Vensim ${ }^{\circledR}$ DSS (Ventana Systems 2012) consists of three interactive sub-models: a) Demand; b) Supply; and c) Desalination. The SD models were formulated by identifying key variables, establishing causal relationships between these variables and finally parameterising these relationships.

The following sections discuss required data, scenarios and how three sub-models compute water supply and demand, and impacts of alternative resources on water security by considering key factors, such as changes in climate, population and diversifying water supply sources.

\subsubsection{Data, Key Variables and Scenarios}

System boundaries are important in identifying the key model input variables as well as deciding which process is endogenous or exogenous. Key variables required for the herein developed SD model were identified through a comprehensive literature review and expert consultations with consultants, water utilities and researchers (Table 1).

The model assumes that the volume and character of water use is mainly determined by five key drivers with varying effects. These are:

- Population growth,

- Desal plants, 
- Traditional water resources,

- Climate change and variability, and

- Changes in water use pattern and demand.

The elements used in SD diagram are mainly classified into flow variables, rate variables, constants, auxiliary variables and table functions. Spatial boundaries of the SD comply with the boundaries of the grid connected SEQ bulk water supply system. The time horizon of the model was selected as 100 years in order to consider the historical long-term cycles of rainfall patterns. Moreover, to eliminate anomalies due to the seasonal variations in reservoir levels, the SD model uses quarterly simulation steps and then aggregates results to produce annual output values.

Data, such as water use per person, annual water supply, capacity of existing water resources, population, available desal capacity, were taken from SEQ Water Strategy report (QWC 2010). Annual inflow data was randomly generated by using the historical data recorded for SEQ between 1890 -2010. The El-Niño and the La-Niña cycles were also taken into account in reflecting wet/dry season impacts on the random inflow data.

The size of population, together with climate variability, is the most important driver in the model. Rate of population growth and magnitude of climate variability strongly influence both supply and demand over time.

Table 1 The key model input variables and range of values for SEQ water supply-demand system

\begin{tabular}{|c|c|c|}
\hline Variable & Units & Range of Values \\
\hline Current population ${ }^{1}$ & Persons & $3.2 \times 10^{6}$ \\
\hline Population growth rate ${ }^{1}$ & $\%$ & $\begin{array}{l}\text { Varying from }-2.5 \text { to } 2.5 \\
\text { Default value: } 1.5\end{array}$ \\
\hline Water use per capita ${ }^{2,6,7}$ & $\mathrm{~L} \mathrm{day}^{-1}$ & $\begin{array}{l}\text { Varying from } 200 \text { to } 450 \\
\text { Default value: } 300-200^{7}\end{array}$ \\
\hline Existing dam capacity ${ }^{2}$ & $\mathrm{hm}^{3}$ & 2,220 \\
\hline Existing desal capacity ${ }^{2}$ & $\mathrm{hm}^{3}$ year $^{-1}$ & 46 \\
\hline Desal capital costs 3 & \$ Billion & Varying from 1.2 to 5 \\
\hline
\end{tabular}


Default value: 1.2

\begin{tabular}{|c|c|c|}
\hline Desal operation $\operatorname{cost}^{3}$ & $\$ / \mathrm{m}^{3}$ & $\begin{array}{l}\text { Varying from } 0.75 \text { to } 2.5 \\
\text { Default value: } 0.95\end{array}$ \\
\hline \multirow{2}{*}{ Dam capital cost ${ }^{4}$} & \multirow{2}{*}{$\$$} & Varying from 1 to 5 \\
\hline & & Default value: 1.7 \\
\hline \multirow{2}{*}{ Dam operation cost ${ }^{4}$} & \multirow{2}{*}{$\$ / \mathrm{m}^{3}$} & Varying from $0.1-0.3$ \\
\hline & & Default value: 0.15 \\
\hline Modelling time horizon & Year & 100 \\
\hline Time interval of simulation & Year & 0.25 \\
\hline \multirow{2}{*}{ Water security index ${ }^{5}$} & & Varying from 1 to 6 \\
\hline & & Default value: 6 \\
\hline \multirow{2}{*}{ Discount rate } & \multirow{2}{*}{$\%$} & Varying from 1.5 to 5.5 \\
\hline & & Default value: 3.5 \\
\hline \multirow{2}{*}{ Size of new desal to be constructed } & \multirow{2}{*}{$\mathrm{hm}^{3}$} & Varying from 50 to 150 \\
\hline & & Default value: 50 \\
\hline \multirow{2}{*}{ Size of new dam to be constructed } & \multirow{2}{*}{$\mathrm{hm}^{3}$} & Varying from 50 to 150 \\
\hline & & Default value: 100 \\
\hline
\end{tabular}

\footnotetext{
Notes:

${ }^{1}$ Queensland Office of Economic and Statistical Research (2011);

${ }^{2}$ QWC (2012); ${ }^{3}$ Stewart (2011); ${ }^{4}$ Moran (2008);

${ }^{5}$ The water security index is the annual demand divided by the accessible storage capacity;

${ }^{6} \mathrm{Per}$ capita consumption including residential and non-residential components;

${ }^{7} 300-200$ means an efficient $300 \mathrm{~L} \mathrm{day}^{-1}$ (200 L day ${ }^{-1}$ residential $+100 \mathrm{~L} \mathrm{day}^{-1}$ non-residential plus system losses) demand in present day reducing to $200 \mathrm{~L} \mathrm{day}^{-1}\left(120 \mathrm{~L} \mathrm{day}^{-1}\right.$ residential $+80 \mathrm{~L}$ day $^{-1}$ non-residential plus system losses) in the 100 year modelling timeframe.
}

A key intention of model development was to allow flexibility, rather than limit users to predefined scenarios. The SD model is capable of simulating a very large number of permutations, based on user choice and the multivariate Monte Carlo simulation technique. Therefore, rather than limiting the users to a set of predefined scenarios, a flexible scenario development approach has been employed, which enables users to modify key variables to accurately assess vulnerability to water scarcity and solution alternatives by applying various scenario parameters.

However, for the purposes of this paper, only ten prescribed scenarios have been selected to illustrate the influence of the more pertinent variables on some of the more likely future scenarios (Table 2). The main variables changed in the ten scenarios were population growth, water usage, water security index (WSI) and the discount rate (\%). 
Table 2. Predefined input values for examined simulation scenarios

\begin{tabular}{lcccc}
\hline Predetermined & $\begin{array}{c}\text { Population } \\
\text { growth }(\%)\end{array}$ & $\begin{array}{c}\text { Water use } \\
\left(\text { L day }^{-1}\right)\end{array}$ & WSI & Discount \\
Scenarios & 2 & 450 & & \\
\hline Demand Scn1 & 2 & 375 & & \\
Demand Scn2 & 1.5 & 450 & & \\
Demand Scn3 & 1.5 & 375 & & \\
Demand Scn4 & 1.5 & $300-200$ & & \\
Demand Scn5 & 1.5 & $300-200$ & 5 & \\
\hline WaterSecurity_Scn1 & 1.5 & $300-200$ & 6 & 3.5 \\
WaterSecurity_Scn2 & 1.5 & $300-200$ & 6 & 5.5 \\
\hline NPV_Scn1 & 1.5 & $300-200$ & 6 & 6 \\
NPV_Scn2 & 1.5 & $300-200$ & 6 & \\
NPV_Scn3 & & & & \\
\hline
\end{tabular}

\subsubsection{Demand Sub-Model}

Projection of future demand is calculated using current per capita water consumption and future population projection. Fluctuation in water consumption as a result of restriction during the drought is also considered by using the historical SEQ water consumption data. Figure 3 shows some drivers affecting and affected by the Annual Water Demand. The model takes into account future variations in Annual Water Demand by simulating changes in key drivers such as climate, population, and water shortage over the planning timescale. Population growth is identified as one of the most significant factors affecting water demand. Changing climate is also critical in influencing water use level. 


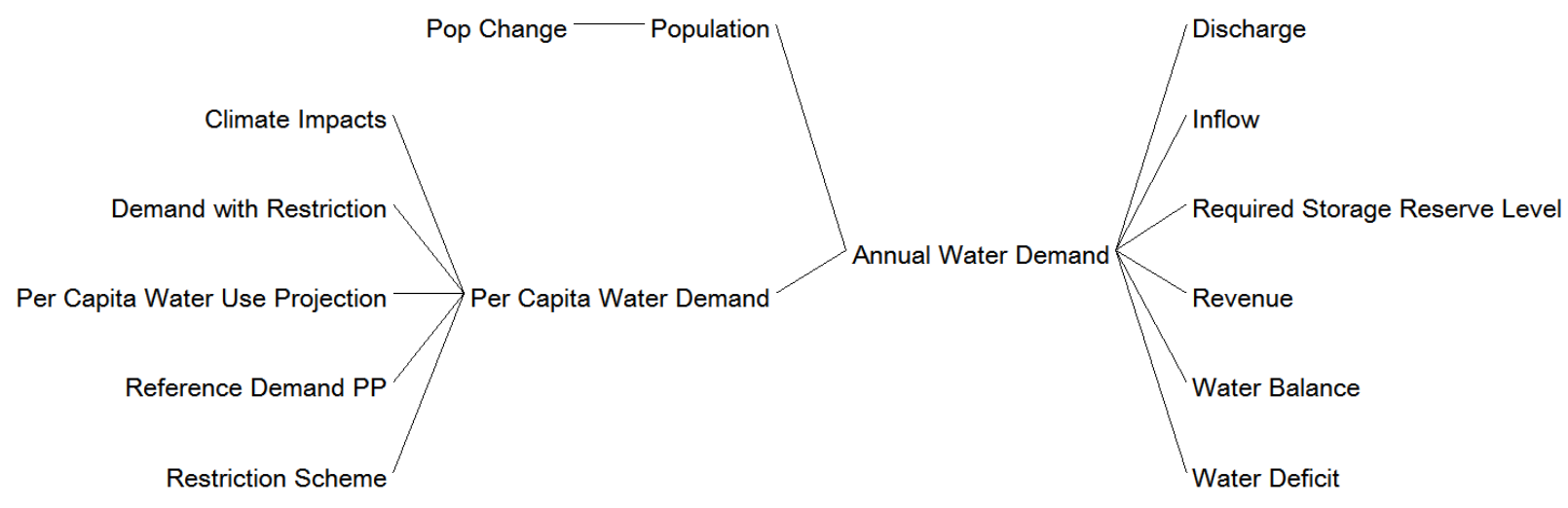

Figure 3. Influence tree for Annual Water Demand variable

Three variables, Annual Water Demand $\left(\mathrm{hm}^{3}\right.$ year $\left.{ }^{-1}\right)$, Population (Person) and Per Capita Water Demand $\left(\mathrm{L} \mathrm{day}^{-1}\right)$, were computed using the following equations:

$$
\begin{aligned}
& A W D=P x W D_{p c} * 365 \\
& P=\int P_{c h} x d t+P_{i} \\
& W D_{p c}=W U P_{p c} x(1+C I)
\end{aligned}
$$

Where $A W D$ is the regional annual water demand $\left(\mathrm{hm}^{3}\right.$ year $\left.{ }^{-1}\right) ; P$ is the population (Person); $P_{c h}$ is the population change $(\%) ; P_{i}$ is the current population (Person), $W D_{p c}$ is the per capita water demand $\left(\mathrm{L} \mathrm{day}^{-1}\right)$; $C I$ is the climate impact factor (ie, the impact of decreased rainfall and increased temperature as a percentage point on water demand and supply); and $W U P_{p c}$ is the per capita water use projection $\left(\mathrm{L} \mathrm{day}^{-1}\right)$.

The Per Capita Water Demand level is planned and implemented by the SEQ water authorities by using demand management techniques, such as pricing and water restrictions. Assumption of $375 \mathrm{~L} \mathrm{day}^{-1}$ (for all uses) includes; residential (230 L day $\left.{ }^{-1}\right)$, non-residential water use and system losses (QWC 2010). The bulk water suppliers' current planning level-of-service demand of $375 \mathrm{~L}$ day $^{-1}$ is lower than the pre-drought total per capita demand of $450 \mathrm{~L} \mathrm{day}^{-1}$. These two demand values were utilised in Demand Scn1 to 4. Demand Scn5 represents a visioned trend of water demand going forward (Table 2). Presently water demand in the region, which was exposed to 
extreme social marketing and retrofitting of water appliances to those of high efficiency, is tracking closer to the 'Target 200' demand which is $200 \mathrm{~L} \mathrm{day}^{-1}$ residential demand and $100 \mathrm{~L}^{\text {day }}{ }^{-1}$ nonresidential demand with system losses, which makes a total present day 'efficient' demand of $300 \mathrm{~L}$ day $^{-1}$. Severe water scarcity events have been a key driver for affected populations to become much more water efficient through regulatory, technological and behavioural reform (Pereira et al. 2009). It is anticipated that climate variability along with rapid regulatory, environmental and technological (i.e. appliance efficiency and enhanced customer information) change will continue current demand reduction trends into the future. Therefore, Demand Scn5 (Table 2) considers a scenario where demand will reduce from the current efficient $300 \mathrm{~L} \mathrm{day}^{-1}$ total per capita demand to $200 \mathrm{~L} \mathrm{day}^{-1}$ (120 L day ${ }^{-1}$ residential plus $80 \mathrm{~L} \mathrm{day}^{-1}$ non-residential plus system losses) over the 100 year modelling period. This has the effect of levelling off total region-wide demand over time even though population growth continues. This reduction in per capita demand over time has a significant influence on the amount of additional supply required to maintain water security in the region.

It should be noted that the model is flexible and also allows users to change these demand values to whatever values they feel may reflect current and future demand using a slider. For example, a user of the SD model may wish to consider a potential water consumption increase due to climate change or variability, which will also cause a temperature increase and rainfall decrease over time as reported by SEQ Water Strategy 2010 (QWC 2010).

In addition to an overall increase in water demand, the potential decrease in and volatility of water supply due to climate change and seasonal/inter-annual climate variability may strain relations between competing water users including agricultural, municipal, industrial, energy, environmental, and recreational. Thus, the magnitude of climate impact on demand ranging from $0 \%$ to $20 \%$ is set and controlled by a slider. As water demand increases, these challenges require water authorities to develop management strategies and supply alternatives to meet these increasing needs. 
According to the Queensland Office of Economic and Statistical Research (2011), the projected annual growth rate averaged over the 45 year period 2011 to 2056 is 1.5 percent. Using this figure, the initial Population Growth Rate was set to $1.5 \%$ and is controlled with a slider (ranging from $2 \%$ to $4 \%$ ) to test the impacts of varying population growth scenarios.

\subsubsection{Supply Sub-Model}

Supply sub-model is used to understand the impacts of changing climate and population growth on rainfall dependent water resources. As shown in Figure 2, supply aggregates both rainfall dependent (surface water and groundwater) and rainfall independent water resources (e.g. desal plants). Supply increases (or decreases) through additional groundwater pumping and surface water storage capacity, which is, however, extensively relies on rainfall, and/or through desal plants as an option for increasing water supply.

Water Budget, Total Annual Water Supply and Water Balance were computed using following equations:

$$
W B==\int(I-D) d t+\left[W S_{\text {in }}\right]
$$

Where: WB: Water Budget $\left(\mathrm{hm}^{3}\right), I$ : Increase in water budget at time $t_{n}\left(\mathrm{hm}^{3}\right), D$ : Decrease in water budget at time $t_{n}\left(\mathrm{hm}^{3}\right)$, and $W S_{i n}$ : Initial water stock at time $t_{0}\left(\mathrm{hm}^{3}\right)$.

Water Budget increases or decreases depending on total annual water supply and annual water demand. Initial Water Stock level as of January 2013, according to BOM (2013), was about 2,000 $\mathrm{hm}^{3}$, which was used to calculate Water Budget over the simulation period.

Annual Water Supply is simulated by considering water storage level. Based on the strategy defined in SEQ Water Strategy report (QWC 2010), the model decides on which supply option should be utilised. For instance, if water storage capacity is $80 \%$ or more, rainfall independent supply resources (desal plant and purified recycled water plant) go into the mothballing stage to reduce the supply cost. However, when the storage level drops below critical $80 \%$ level, then desal 
plants becomes active and supplies water into the water grid. As shown in the following logic equation, when Mothballing equals 1, then rainfall independent supply resources become inactive; if not, then rainfall independent supply resources gradually become active by using the $80 \%$ water storage level as a starting point.

IF Mothballing $=1, T A W S=R D S$, ELSE TAWS $=R D S+R I S \times M_{\text {ind }}$

Where: TAWS: Total annual water supply $\left(\mathrm{hm}^{3}\right.$ year $\left.^{-1}\right), R D S$ : Rain dependent supply $\left(\mathrm{hm}^{3}\right.$ year $\left.{ }^{-1}\right)$, RIS: Rain independent supply $\left(\mathrm{hm}^{3}\right.$ year $\left.^{-1}\right)$, and $M_{\text {ind }}$ : Mothballing index (\%)

And, the Annual Water Balance is calculated by simply subtracting the Annual Water Demand from Total Annual Water Supply:

$A W B=T A W S-A W D$

Where: AWB refers to annual water balance $\left(\mathrm{hm}^{3}\right.$ year $\left.{ }^{-1}\right)$

\subsubsection{Desalination Plants Sub-Model}

This sub-model is designed to understand how swiftness of decision on using existing and building new desal plants would help closing the supply gap. The sub-model through an interactive interface containing a range of scenario control keys and output graphs allows users to change input parameters to analyse the behaviour of the complete system. The construction decision of new desal plants is lengthy and influenced by many drivers. Due to limited availability of suitable sites for constructing additional dams in SEQ (QWC 2010), future water supply alternative in the model is mainly limited to building desal plants.

As shown in Figure 4, depending on the water storage level, and water supply deficit, the model simulates the impacts of Desal Construction Decision on desal construction planning and 
completion stages, thereby how additional desal supply would meet the increasing demand and provide water security.

Three state variables, Planned Desal, Desal in Construction and Desal Completed are crucial for responding rapidly to widening supply gap. Thus, timing of decision on planning and swift action to complete building new desal plants would be conclusive for providing and sustaining water security in the long term.

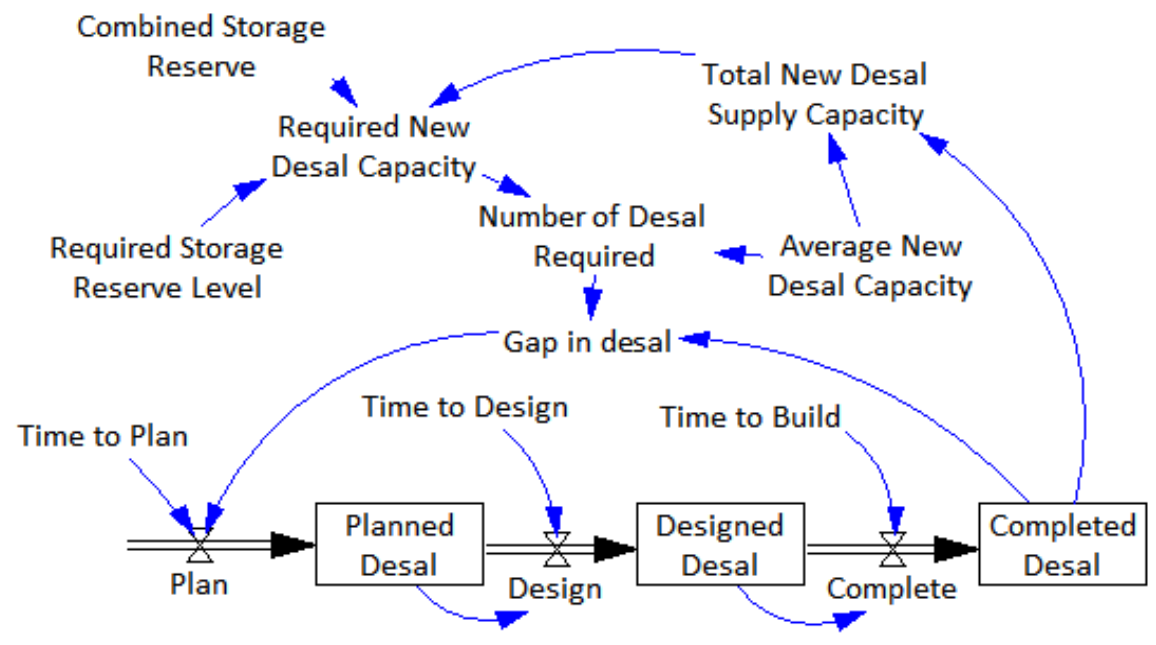

Figure 4. Desalination sub-model used to analyse the impacts of desalination plants on water balance

According to QWC (2010), the construction of major new supplies would be triggered as part of a drought response strategy. Therefore, in this model, the construction of the desal supply source will be triggered by the Storage Capacity Fraction, which is calculated by using supply, demand and accessible storage capacity. It is assumed that new desal construction planning would start at the trigger point, $40 \%$ of the storage capacity. Then, using the equations shown in Table 3 , different stages of desal plants construction decision and execution are calculated: 
Table 3 Equations used to calculate desal plants construction decision and execution

Equations

Planned Desal $=\int(+$ Planning - Building $) d t+[$ Planning * Time to Plan]

Planning $=\operatorname{MAX}(0$, Replacement Desal $+($ Gap in Desal $/$ Time to Respond $))$

Desal in Construction $=\int($ Building-Completing $) d t+[$ Building $*$ Time to Build]

Building = Planned Desal $/$ Time to Plan

Desal Completed $=\int(+$ Completing-Demolishing $) d t+[0]$

Completing $=$ Desal in Construction $/$ Time to Build

Demolishing $=$ Desal Completed $/$ Average Desal Life

\section{RESULTS AND DISCUSSION}

\subsection{Forecast for Water Supply and Demand}

The first step in forecasting water demand was estimating the size and future growth of the population in SEQ. To estimate the future population growth in the SEQ, the available data about regional local population growth is taken into account. Projection of future demand was calculated using current per capita water consumption and future population projections. Under the 2 percent growth rate scenario, SEQ's population increases from 3.2 million to 4.56 million in 2031, 6.78 million in 2051, and 21.8 million in 2110. This finding is consistent with the Queensland Government projection. Under a slower 1.5 percent population growth rate scenario, the SEQ population is estimated to increase 4.13 million by $2021,5.57$ by 2051 , and 13.6 million by 2110 .

Per capita water use data are taken from the SEQ Water Strategy report (QWC 2010; QWC 2012). The report defines three per capita consumption scenarios, these are: 1) Target 200 demand: $300 \mathrm{~L} \mathrm{day}^{-1}$ (all uses); 2) 'Level of Service (LOS) objectives' demand: $375 \mathrm{~L} \mathrm{day}^{-1}$ (Including $230 \mathrm{~L}$ day $^{-1}$ residential and, $145 \mathrm{~L} \mathrm{day}^{-1}$ non-residential water use and system losses); and 3) Pre-drought demand: $450 \mathrm{~L} \mathrm{day}^{-1}$ (all uses). Considering water efficiency trends discussed above, the already 
efficient $300 \mathrm{~L} \mathrm{day}^{-1}$ demand scenario would most likely become closer to $200 \mathrm{~L} \mathrm{day}^{-1}$ in the modelling timeframe.

Based on the projections for population and per capita water consumption and SEQ water strategy report demand scenarios, the Annual Water Demand is simulated for five predefined scenarios as detailed in section 2.2.1 (Table 2). The result indicates that total annual water demand is highly sensitive to population growth, per capita water use and climate change and variability. As shown in Figure 5, the Annual Water Demand at the end of the 100 year simulation period is ranging from about 1,000 $\mathrm{hm}^{3}$ year ${ }^{-1}$ (Demand Scn5) to 3,651 $\mathrm{hm}^{3}$ year $^{-1}$ (Demand Scn1). 40 years from today, the minimum demand level is equal to 25 percent of current SEQ accessible storage capacity $\left(2,220 \mathrm{hm}^{3}\right)$ while the maximum demand level would account for 50 percent. In addition, a further increase in water demand due to increasing temperature is taken into account in the model by using a number of climate variability scenarios ranging from zero impact to 20 percent extreme impact. Figure 5 illustrates the importance of sustained water demand reduction through water efficiency measures (i.e. Demand Scn 5) as a key strategy for flattening the demand growth curve for fast growing urban populations such as SEQ.

Annual Water Supply is simulated by considering the water storage level (Figure 6). For each time period, inflows data are randomly generated based on historical data published in the SEQ Water Strategy report 2010 by using triangular distribution. This provides a consistent approximation of historical inflows pattern. Based on the strategy defined in SEQ Water Strategy report (QWC 2010), the model decides on which supply option should be utilised. For instance, if water storage capacity is $80 \%$ or more, rainfall independent supply resources (desal plant and purified recycled water plant) go into the mothballing stage to reduce the supply cost. However, when the storage level drops below the $80 \%$ level, then desal plants becomes active and supplies water into the water grid. 


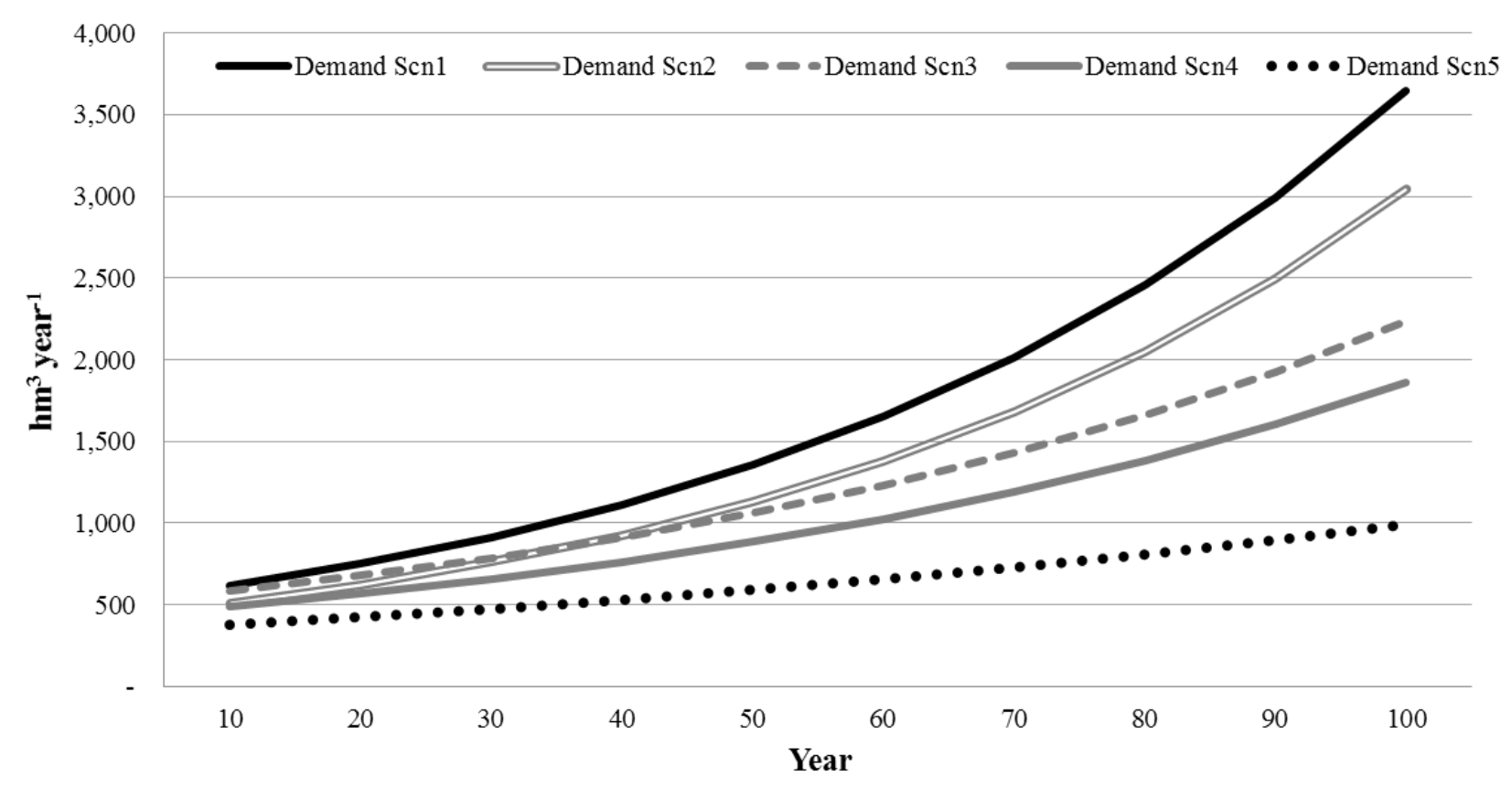

Figure 5. Annual water demand under five scenarios $\left(\mathrm{hm}^{3}\right.$ year $\left.{ }^{-1}\right)$

Although Australia's dams are large enough to hold four times the nation's annual consumption, reservoir water levels are highly erratic due to frequent drought and extreme rainfall variability. Further, climate change and drought are depleting reservoir levels due to changing rainfall patterns and associated reductions in runoff (NCEDA 2010). According to the simulation results, water supply will be far below the drought storage levels (black line and dotted line) due to high inflow variability and growing demand. Under the high demand scenario, the water storage will drop below the drought storage level rapidly. According to the SEQ water strategy, the combined SEQ Water Grid drought storage reserve underpins the drought response plan. The drought storage reserve is sized to provide, in conjunction with climate resilient sources, a minimum of 36 months' supply of water at a restricted demand. In this model, the drought storage level is calculated based on annual demand without restriction. 


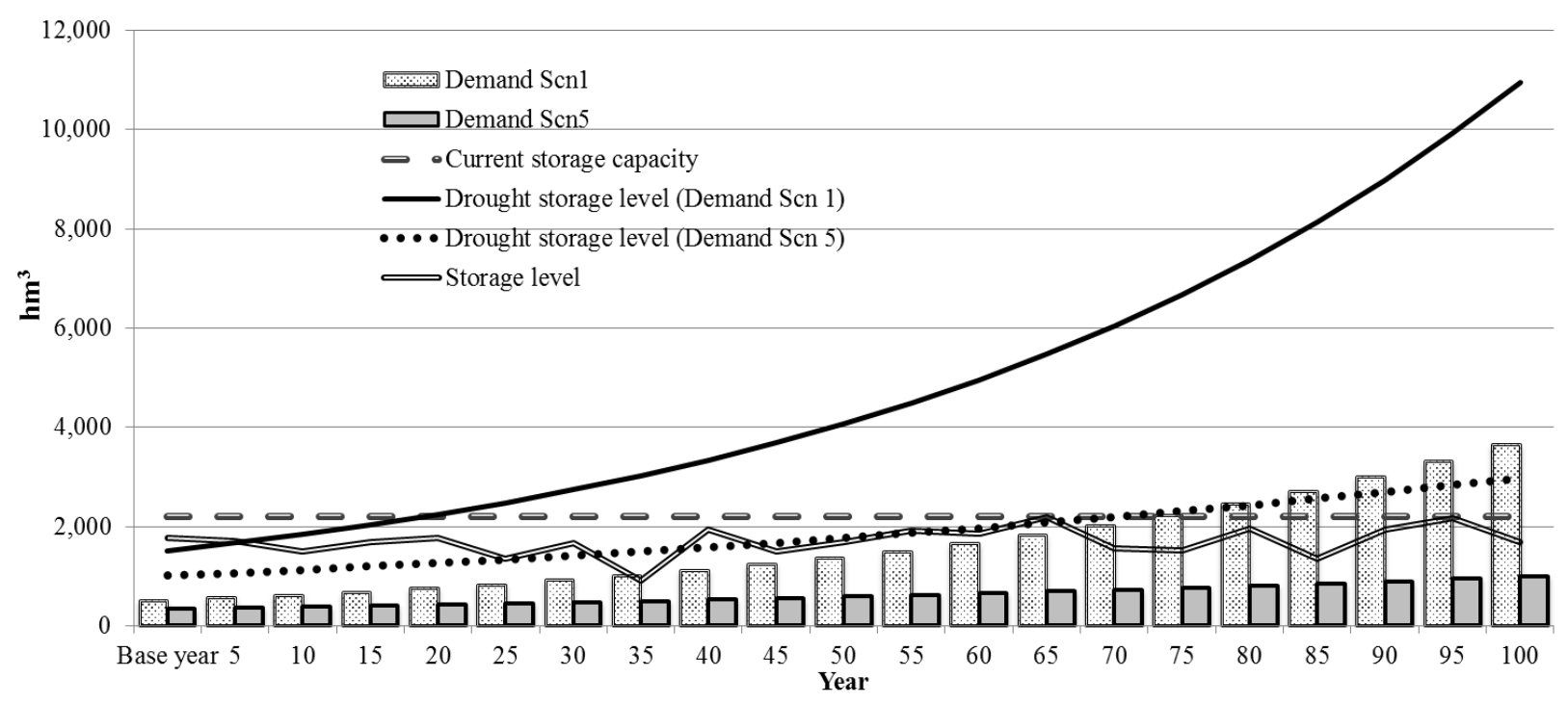

Figure 6 Projections of drought storage volumes under two demand scenarios

Figure 6 shows that, under the high demand and population growth scenario (Demand Scn1), the level of drought storage reserve (black line) would reach the current accessible water storage level (grey dashed line) within the next 20 years, while under the efficient and the reducing per capita demand trend and population growth scenario (Demand Scn5), the level of drought storage reserve (black dotted line) would reach the current accessible water storage level (grey dashed line) within the next 65 years. The annual demand for water would be equal to the maximum level of accessible water storage within 70 years (high demand). Accordingly, having a large storage capacity generally does not provide water security as observed during the millennium drought between 2002 and 2009, especially when persistent droughts reduce the availability of water sharply. That is, without sufficient rainfall, large reservoirs of SEQ formed behind dams are nothing more than costly investments.

Using the five demand scenarios discussed earlier, required desal supply capacity, combined storage reserve capacity with and without desal supply, and desal utilisation level were modelled (Figure 7). The simulation shows that there is a need for a new desalinated water supply source after five years. Depending on the population growth and per capita water demand, this requirement ranges from 150 to $850 \mathrm{hm}^{3}$ year-1 after the first 50 years (about 17 desal plants for the high demand scenario, each with a $46 \mathrm{hm}^{3}$ year ${ }^{-1}$ capacity of the existing desal plant located in the suburb of 
Tugun, SEQ). According to the SEQ water strategy calculation (QWC 2010), under the high series population growth and LOS objectives scenario $\left(375 \mathrm{~L} \mathrm{day}^{-1}\right)$, by 2056 the gap between supply and demand would be $410\left(\mathrm{hm}^{3}\right.$ year $\left.{ }^{-1}\right)$ without additional supply. Under the Demand Scn4, our simulation results show that this gap would be $450 \mathrm{hm}^{3}$ year ${ }^{-1}$, which is slightly higher than the SEQ water strategy 2010 finding.

Total required desal capacity and the levels of the desal plant utilisation over the examined period were simulated for three demand scenarios (i.e. Demand Scn1, Demand Scn4 and Demand Scn5 representing high, medium and low level demand ) respectively.

The Demand Scn5, consistent with the Target 200 Demand defined in the SEQ Water Strategy (QWC, 2012), represents an average present day regional residential water use of $200 \mathrm{~L}^{\text {day }}{ }^{-1}$ over the next five years and assumes a low rebound in non-residential water use to a regional average of $100 \mathrm{~L} \mathrm{day}^{-1}$ (i.e. $300 \mathrm{~L} \mathrm{day}^{-1}$ total). Further, this scenario considers a gradual reduction in demand over the 100 year period to $200 \mathrm{~L} \mathrm{day}^{-1}\left(120 / \mathrm{p} / \mathrm{d}\right.$ residential $+80 \mathrm{~L} \mathrm{day}^{-1}$ non-residential plus system losses) in 100 years. Under this scenario, simulation results show that, in the first 50 years, about 3 Tugun sized plants would be required, which increases to 8 in 100 years. This is only $15 \%$ (i.e. 8/52) of the additional supply capacity required if consumers stubbornly retained historical levels of demand.

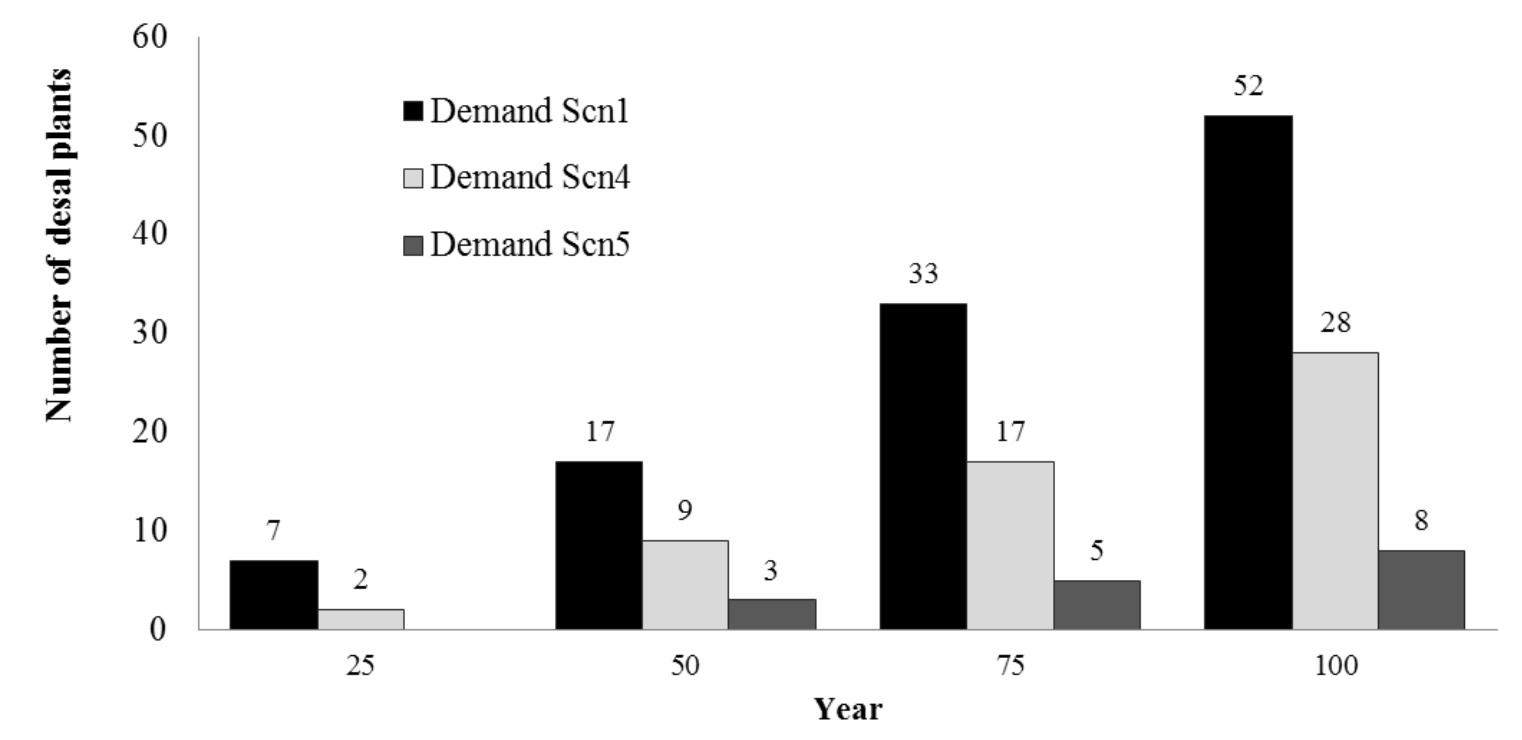

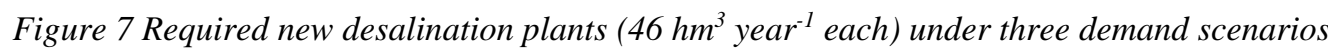


The simulation results demonstrate that, with the growing population having sustained high water consumption and medium-term periods without sufficient rainfall, the existing extensive portfolio of large dam storage reservoirs that exist in SEQ will be vastly inadequate. On the other hand, at least in the first 50 years under the low demand scenario, extensive desalinated supply expansion is not shown to be essential but some limited expansion would definitely serve to increase the level of water security afforded by the SEQ region. In summary, Figure 7 highlights the monetary benefits of coupling a strong and ongoing demand efficiency agenda (Demand Scn5) with a growing proportion of rain-independent supply in a regions overall supply portfolio. The next section demonstrates this argument further.

\subsection{Water Security}

Since the accessible volume of water at any given time is one of the most important factors affecting water security, one indicator of water supply security used in this research is the Water Security Index (WSI). This index reflects the ratio of water storage to annual usage. A higher WSI is required where there is a higher uncertainty around reliable annual rainfall, which was the case in SEQ. Therefore, the construction of new supplies is triggered at certain accessible volume thresholds as part of a response to meet demand in order to ensure continuity of supply regardless of climatic variability. The model calculates the WSI based on Marsden and Pickering (2006) study reporting the ratios of water storage to annual usage for major Australian cities. The WSI varies between one and six, with six indicating that to maintain reliable water supply, water storage capacity needs to be six times annual usage to provide reliability of supply given climate variability. In 2006, it was estimated that this ratio for SEQ was six, consequently the model uses six as a default WSI value. The sensitivity of the model to the index varying between one and six has been explored in this study, but only results with an index of five and six have been reported since this 
range is the most appropriate for the region under examination. Note that the most efficient Demand Scn5 was used for water security and NPV modelling.

Given these baseline assumptions, Figure 8 shows the additional water storage capacity that would be required for SEQ over the next one hundred years. The additional storage capacity required is particularly sensitive to assumptions regarding the WSI. Under this status quo scenario, it is assumed that the future supply will rely on rain dependent supply and there will be no new desal capacity investment. In Figure 8, the sensitivity of future water requirements to assumptions regarding the water security index is illustrated with comparison of additional storage capacities with a WSI of 5 and 6 . As indicated, a WSI of 5 is based on the per capita water demand level in 2006.

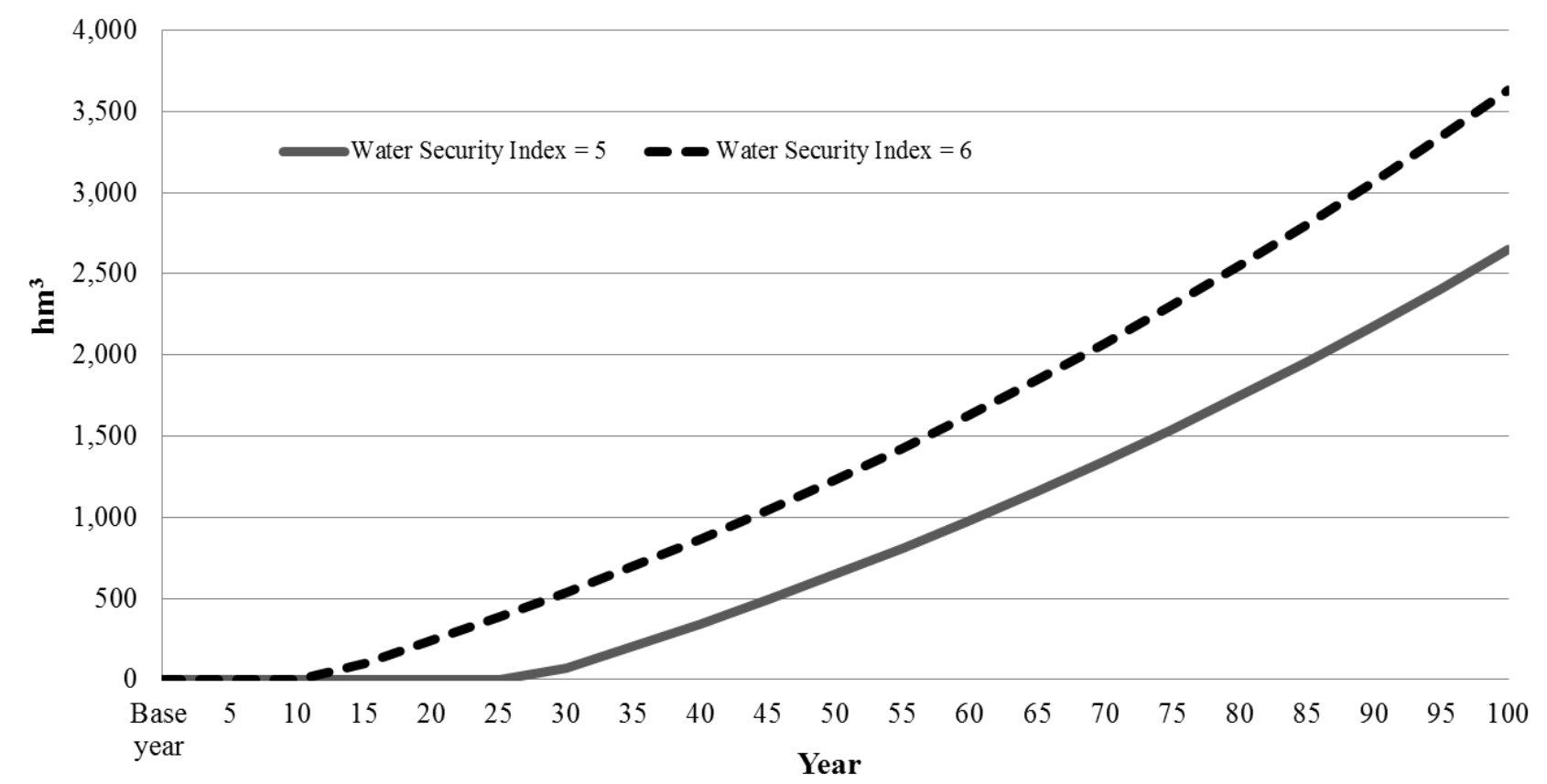

Figure 8 Required additional storage capacity to maintain water security for two scenarios (WSI=5 and WSI=6)

As shown in Figure 8, with a WSI of 5 (grey line), the SEQ region would require additional water capacity in 30 years' time, however, if this index is 6 (dotted line), the additional capacity would be required in 15 years' time. This clearly illustrates the sensitivity of the model to the assumption regarding the WSI. In either case, these results illustrate the need for long term planning in order to meet the challenges of likely water shortfalls between demand and supply. As the 
population increases from 3.2 million to 13.6 million, with a WSI of 5 , the total additional water supply required over the 100 year period would likely to increase by $2,648 \mathrm{hm}^{3}$, and for a WSI of 6 , this rises to $3,631 \mathrm{hm}^{3}$ under a low demand scenario (Demand Scn5). Given that dams need large land areas, catchments and rivers, the construction of large dams to maintain water security could be highly unlikely due to lack of suitable sites. Reducing reliance on surface water and utilising rain-independent supply options, such as desal plants or large-scale centralised recycling plants, can potentially reduce the required level of water security as they are more reliable in providing water supply regardless of precipitation trends and variability. As a result, desal plants would become increasingly economic relative to dams as discussed in the following section.

Further, the forecast future water shortages show that in the absence of long term water supply augmentation planning, water shortages are likely to occur. The magnitude of the shortages is such that demand management strategies alone will not be able to sufficiently address the future imbalance between water demand and supply.

\subsection{NPV Cost of Water Supply Augmentation}

Analysis of long-term planning decisions requires assumptions about the discount rate, especially when the costs are borne in a different time frame than the benefits are received. This is particularly apparent in the case of water resource planning where the timing and size of large infrastructure investments influences analysis of water supply alternatives. Figure 9 shows the sensitivity of the results of the comparison of water supply augmentation costs between dam construction and investing in new desal capacity (including both operating and capital investment costs). 


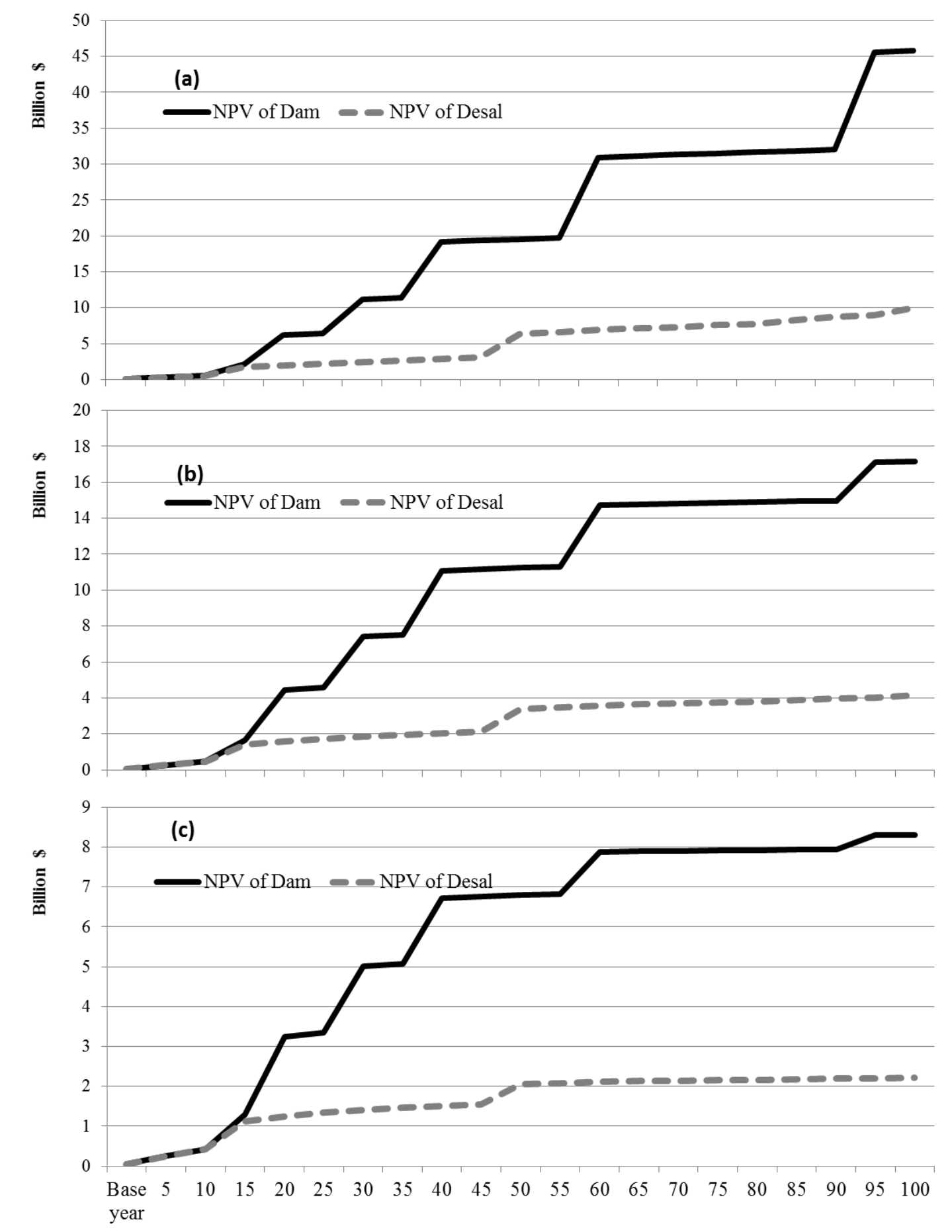

Figure 9 Comparison of the costs of supply alternatives under three NPV scenarios: $(a)$ discount rate $=1.5 \% ;(b)$ discount rate $=3.5 \%$; and $(c)$ discount rate $=5.5 \%$

This analysis is based on the status quo assumptions outlined in Section 2.2.1 (Table 1) and a WSI of 6 . The impact of discount rates of $1.5 \%, 3.5 \%$ and $5.5 \%$ have been explored. This is in line with the literature which suggests that lower discount rates are more appropriate over longer time horizons (Harrison 2010; Weitzman 1998; Weitzman 2013). Further, Harrison (2010) showed 
discount rates in international practice varying from 1 to 15 per cent. The lowest discount rates are generally used in developed countries ranging from 2 to 6 percent (i.e. the US Environmental Protection Agency recommends a discount rate of 2-3 per cent, and no discounting for intergenerational projects with a sensitivity testing with 2-3 per cent and 7 per cent). This suggests that lower rates are more appropriate for long-term public projects given the lower risk associated with public sector investments.

As expected, the higher the assumed discount rate, the lower the net present value of the costs of both dam construction and building desal capacity. With a $1.5 \%$ discount rate, the net present value investment costs over the 100 year period are $\$ 45.8$ billion for dam costs compared to $\$ 9.94$ billion for desal costs (Figure 9-a). This can be compared with net present value costs of $\$ 17.16$ billion for dam costs and $\$ 4.14$ billion for desal costs with a 3.5\% discount rate; and $\$ 8.30$ billion for dam costs and \$ 2.22 billion for desal costs with a 5.5\% discount rate (Figure 9-b and Figure 9c).

In each case, in the longer term, the cost of a desal investment in water supply augmentation is considerably lower than the cost of dam construction. Noticeably, over the longer time horizon, the cost comparison drastically changes in favour of desal. The lower the assumed discount rate in the analysis, the more favourable the investment in desal becomes. This is because the analysis is influenced by the timing of the required investment in supply augmentation.

\section{CONCLUSION}

This paper detailed the development of an SD model built to explore the behaviour of the SEQ water resource system over the next 100 years under systemic change brought about by demand trends, climate variability and population growth. In this context, it has been demonstrated that the SD framework allows rapid evaluation of the effects of a range of planning scenarios through providing realistic visualisation of how water supplies and demands could change over time. Thereby, the framework would improve decision makers' ability to develop sustainable water 
resource management strategies, and thus respond to water scarcity in a timely manner to optimise supplies given the various constraints. The current supply-side orientated approach to water governance was found to be ill-equipped to cope with these changes, leading to economic hardship and chronic water shortages. A sustained water efficiency program whereby demand is reduced over time through better social marketing and efficient appliance technologies plays a significant role in maintaining water security in rapidly growing urban cities.

Further, desal plants may be a useful insurance policy for bridging the gap between supply and demand, particularly during times of drought. Further, this rain-independent supply alternative better handles uncertainty surrounding water supply resources due to high rainfall variability, but like any insurance policy, this would mean that they would not be fully utilised or even sit idle for a few years and then be called into action in the dry weather cycles.

Finally, it has also been found that constructing dams instead of desal plants to maintain a certain level of water security (i.e. WSI $=6)$ would incur a higher unit cost $\left(\$ / \mathrm{m}^{3}\right)$ when modelling these long life cycles due mainly to the regions high rainfall variability. Choosing higher discount rates would reduce the attractiveness of desalinated supply expansion when compared to dams, but, in the longer term, it would still be considerably lower than the cost of dam construction.

It must be noted that the context of water security assessment presented herein is not unique to SEQ, or Australia for that matter. Therefore, because a system dynamics approach has been used, this provides a framework for assessing water security for any situation where a water supplydemand-climate nexus conundrum exists.

\section{ACKNOWLEDGEMENT}

This research, is part of a study on desalinated water in Australian bulk water supply networks, funded by a grant from the National Centre of Excellence in Desalination Australia (NCEDA) to the Alfred Deakin Research Institute (ADRI) at Deakin University, in a project jointly managed with the 
Smart Water Research Centre at Griffith University, and with technical cooperation from AECOM Ltd.

The authors gratefully acknowledge the travel funding from the Griffith Climate Change Response Program (GCCRP).

\section{REFERENCES}

ABS (2010) Measures of Australia's Progress. Australian Bureau of Statistics. http://www.abs.gov.au/ausstats/abs@.nsf/Lookup/by\%20Subject/1370.0 2010 Chapter Water\%20s torage\%20(6.3.6.2). Accessed February 2013

ABS (2012) 2012 Year Book Australia vol ABS Catalogue No. 1301.0. The Australian Bureau of Statistics, Canberra, Australia

Beal C, Stewart RA (2011) South East Queensland Residential End Use Study: Final Report. Gold Coast, Australia

BOM (2013) Water storage. Commonwealth of Australia 2012, Bureau of Meteorology. http://water.bom.gov.au/waterstorage/awris/. Accessed January 2013

Borshchev A, Filippov A From System Dynamics and Discrete Event to Practical Agent Based Modelling: Reasons, Techniques, Tools. In: The 22nd International Conference of the System Dynamics Society, Oxford 2004.

Britton TC, Stewart RA, O'Halloran KR (2013) Smart metering: enabler for rapid and effective post meter leakage identification and water loss management J Clean Prod 54:166-176 doi:DOI 10.1016/j.jclepro.2013.05.018

Burton I, Huq S, Lim B, Pilifosova O, Schipper EL (2002) From Impacts Assessment to Adaptation Priorities: the Shaping of Adaptation Policy Climate Policy 2:145 -159

Cavana RY, Clifford LV (2006) Demonstrating the utility of system dynamics for public policy analysis in New Zealand: the case of excise tax policy on tobacco Syst Dynam Rev 22:321-348 
Fiddaman T (1997) Feedback Complexity in Integrated Climate-Economy Models. Massachusetts Institute of Technology

Fiddaman TS (2002) Exploring policy options with a behavioral climate-economy model Syst Dynam Rev 18:243-267 doi:Doi 10.1002/Sdr.241

Fielding KS, Spinks A, Russell S, McCrea R, Stewart R, Gardner J (2013) An experimental test of voluntary strategies to promote urban water demand management Journal of Environmental Management 114:343-351 doi:DOI 10.1016/j.jenvman.2012.10.027

Ford A (2005) Simulating the impacts of a strategic fuels reserve in California Energ Policy 33:483-498

Forrester JW (1961) Industrial dynamics. (Students' edition) edn. MIT Press, Cambridge, Mass

Franck TR (2009) Coastal Communities and Climate Change" A Dynamic Model of Risk Perception, Storms and Adaptation. Massachusetts Institute of Technology

Gharib S (2008) Synthesizing System Dynamics and Geographic Information Systems in a new method to Model and Simulate Environmental Systems. University of Bergen

Girard M, Stewart RA (2007) Implementation of pressure and leakage management strategies on the Gold Coast, Australia: Case study Journal of Water Resources Planning and Management 133:210-217 doi:Doi 10.1061/(Asce)0733-9496(2007)133:3(210)

Gurung TR, Sharma A (2014) Communal rainwater tank systems design and economies of scale J Clean Prod 67:26-36 doi:http://dx.doi.org/10.1016/j.jclepro.2013.12.020

Harrison M (2010) Valuing the future : the social discount rate in cost-benefit analysis : visiting research paper. Australia Productivity Commission Visiting Researcher Paper, vol (April 2010). Productivity Commission, Melbourne

Hennessy K et al. (2007) Australia and New Zealand.

Homer J, Hirsch G, Milstein B (2007) Chronic illness in a complex health economy: the perils and promises of downstream and upstream reforms Syst Dynam Rev 23:313-343 doi:Doi 10.1002/Sdr.379 
Homer J, Hirsch G, Minniti M, Pierson M (2004) Models for collaboration: how system dynamics helped a community organize cost-effective care for chronic illness Syst Dynam Rev 20:199-222 doi:Doi 10.1002/Sdr.295

Loucks DP, van Beek E (2005) Water resources systems planning and management : an introduction to methods, models and applications. Studies and reports in hydrology / Unesco Publishing. Unesco, Paris

Marchand M (2009) Modelling coastal vulnerability : design and evaluation of a vulnerability model for tropical storms and floods. Deltares select series,, vol 05. IOS Press, Amsterdam

Marsden J, Pickering P (2006) Securing Australia's urban water supplies opportunities and impediments

Moran A (2008) Water supply options for Melbourne - An examination of costs and availabilities of new water supply sources for Melbourne and other urban areas in Victoria. Institute of Public Affairs, Melbourne, Australia

NCEDA (2010) Australian desalination research roadmap. National Centre of Excellence in Desalination, Murdoch University, Rockingham, Western Australia

NWC (2006) Australia's water supply status and seasonal outlook

Pereira LS, Cordery I, Iacovides I (2009) Coping with Water Scarcity - Addressing the Challenges. Springer, Dordrecht. doi:10.1007/978-1-4020-9579-5 5

Queensland Office of Economic and Statistical Research (2011) Local government areas : Queensland Government population projections to 2031. 2011 edn. Office of Economic and Statistical Research, City East, Qld.

Queensland Treasury (2011) Population projections to 2031: local government areas, 2011 edn.,

QWC (2010) South East Queensland water strategy. Queensland Water Commission, City East, Qld.

QWC (2012) South East Queensland Water Strategy - Annual Report 2012. Queensland Water Commission, City East, Qld. 
Roberts N (1983) Introduction to computer simulation : the system dynamics approach. Addison-Wesley, Reading, Mass.

Sahin O (2011) Dynamic Assessment of Coastal Vulnerability and Adaptation to Sea Level Rise: An Integrated Spatial-Temporal Decision Making Approach. Griffith University

Sahin O, Mohamed S Decision dilemmas for adaptation to sea level rise: How to, when to? In: Industrial Engineering and Engineering Management, 2009. IEEM 2009. IEEE International Conference on, 811 Dec. 2009 2009. pp 1622-1626

Sahin O, Mohamed, S., (2013) A spatial temporal decision framework for adaptation to sea level rise Environ Modell Softw In Press

Sterman JD (2008) Economics - Risk communication on climate: Mental models and mass balance Science 322:532-533 doi:DOI 10.1126/science.1162574

Stewart R (2011) Verifying the end use potable water savings from contemporary residential water supply schemes. National Water Commission Waterlines Report No. 61, Australian Government, Canberra

Stewart RA, Willis RM, Panuwatwanich K, Sahin O (2011) Showering behavioural response to alarming visual display monitors: longitudinal mixed method study Behaviour \& Information Technology:117 doi:10.1080/0144929x.2011.577195

Ventana Systems (2012) Vensim DSS, 6.0b edn. Ventana Systems, Inc., Harvard, MA

Vieira AS, Beal CD, Ghisi E, Stewart RA (2014) Energy intensity of rainwater harvesting systems: A review Renew Sust Energ Rev 34:225-242 doi:DOI 10.1016/j.rser.2014.03.012

Wasimi SA (2010) Planning for a Large Dam Project: The Case of Traveston Crossing Dam Water Resources Management 24:2991-3015 doi:DOI 10.1007/s11269-010-9591-2

Weitzman ML (1998) Why the far-distant future should be discounted at its lowest possible rate J Environ Econ Manag 36:201-208 
Weitzman ML (2013) Tail-Hedge Discounting and the Social Cost of Carbon J Econ Lit 51:873-882 doi:10.1257/jel.51.3.873

Willis R, Stewart R, Panuwatwanich K, Jones K, Kyriakides A (2010) Alarming visual display monitors affecting shower end use water and energy conservation in Australian residential households Resources, Conservation and Recycling 54:1117-1127

Willis RM, Stewart RA, Giurco DP, Talebpour MR, Mousavinejad A (2013) End use water consumption in households: impact of socio-demographic factors and efficient devices J Clean Prod 60:107-115 doi:http://dx.doi.org/10.1016/j.jclepro.2011.08.006

Willis RM, Stewart RA, Panuwatwanich K, Williams PR, Hollingsworth AL (2011a) Quantifying the influence of environmental and water conservation attitudes on household end use water consumption Journal of Environmental Management 92:1996-2009 doi:DOI 10.1016/j.jenvman.2011.03.023

Willis RM, Stewart RA, Williams PR, Hacker CH, Emmonds SC, Capati G (2011b) Residential potable and recycled water end uses in a dual reticulated supply system Desalination 272:201-211 doi:DOI 10.1016/j.desal.2011.01.022

Zhang B (2008) A Study of GIS-SD Based Temporal-Spatial Modelling Of Water Quality In Water Pollution Accidents. Paper presented at the ISPRS Congress Beijing 2008, Proceedings of Commission II, Beijing 